\title{
Free "global university" launched
}

I t's being billed as the world's first "free, largest and most accessible high-quality university."

The ultimate aim, organizers say, is to create a vehicle by which people in the developing world who don't readily have access to medical education can become physicians.

For now, though, organizers are confining their efforts to providing a somewhat amorphous measure of public health education, including a Master of Public Health degree that will be offered in conjunction with Jilin University of China and the Public Health Foundation of India; "certificate" programs in adolescent health, cardiovascular disease prevention, climate change and health, urology, general surgery and prenatal care; along with a basic science and a "prehealth professional" certificate.

The long-term goal is to offer full medical degrees to people in developing countries who find the cost of medical education daunting and access all but impossible, says Dr. Erika Frank, one of the architects of the initiative and professor at the School of Population and Public Health at the University of British Columbia in Vancouver, which in 2006 launched a free online searchable database of health educational materials called Health Sciences Online (http://hso.info).

Under a pilot now being implemented, organizers hope their proposed "Global University" (http://globaluni.info/) will begin offering an online Master's of Public Health and several certificate programs later this year or early in 2012.

The team is currently undertaking "preliminary forays" into how it might establish and offer an accredited MD degree and residencies, Frank says.

Dr. Kate Tairyan, who'll be the dean of the Master of Public Health program, says there's a need for a more egalitarian method of educating doctors and health professionals.

"Brick and mortar universities are not addressing the need for health professionals today in the world, so we

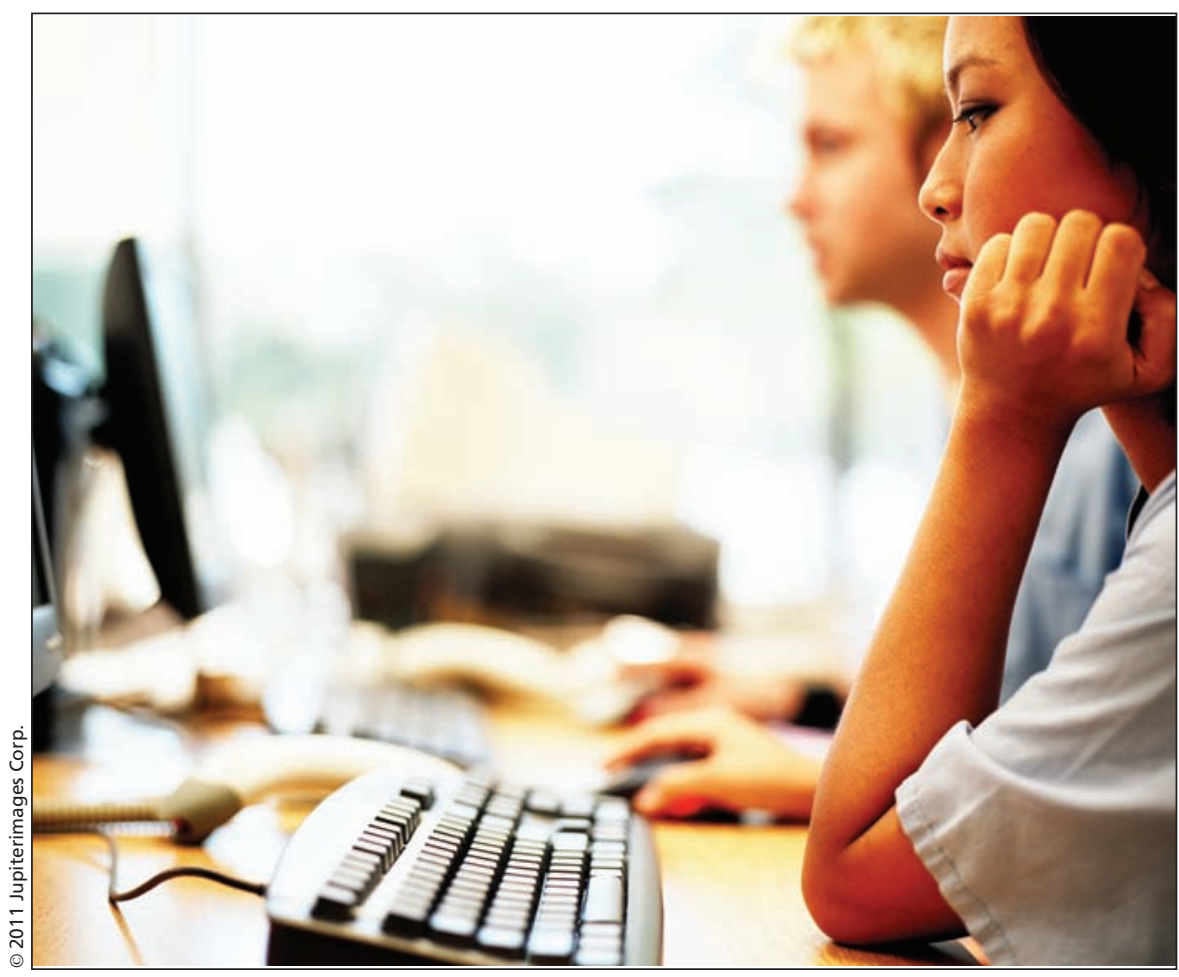

The people proposing to create a free "global university" hope to offer an online Master's of Public Health program later this year or in early 2012.

have to come up with innovative new ways and technologies to solve this problem, to reach people who would otherwise be marginalized," adds the postdoctoral fellow at UBC and content director of Health Sciences Online.

The various certificate programs will be accredited in conjunction with such partners as UBC, the American College of Preventive Medicine, Physicians for Social Responsibility, the Center for Surgery and Public Health at Harvard's Brigham and Women's Hospital in Cambridge, Massachusetts, the University of Zambia, the College of Surgeons of East, Central and Southern Africa, the Medical Women's International Association, Stanford University in Palo Alto, California, and the World Health Organization.

Pilots will be undertaken in China, Colombia and Kenya, among other countries, Tairyan says.

"Our motto is "democratizing knowledge,", Franks says. "We have this very 'assembly line' concept where health professionals have to be created at a particular place, and they have to be entered in June and extruded in July, and there is no reason for either the temporal kinds or the geographical kinds of constraints anymore."

Curricula were assembled from the Health Sciences Online database, which is comprised of over 50000 hand-selected learning materials donated by such organizations as the United States Centers for Disease Control and Prevention, the World Bank, and the World Medical Association.

In preparation for its long-term plans to offer MD degrees, organizers say they are developing partnerships with hospitals and schools around the world that might be in a position to offer residencies.

"The idea is that we do a lot of the kinds of self-learning that one would do anyway with a book or with computer-aided instruction, but we organize 
the knowledge transfer component of it, and then everybody has hands-on training with a local mentor, just as they would if they were being trained in Vancouver or Ottawa," says Frank. "They'll learn what activities they need to do from us, but they'll practice them locally."

Tairyan forecasts that students will sometimes have to establish their own connections with local supervisors. "In developing countries, medical professionals are so overloaded because there's a shortage of health professionals, and they would be happy to have someone who already has a lot of the knowledge base and training and can help them," she says. "There are many opportunities for students to help their mentors and mentors who benefit from having students around them."

Frank expects that prospective medical students will still have to score well on a Medical College Admission Test and ultimately, pass medical boards in order to be eligible for licensure, even in developing countries.

Dr. Eduardo Montana Jr., Georgiabased pediatric cardiologist and the North and South American liaison for Global University, says the intent is not to create new or unusual competencies but to convert "them into a virtual format with full access that can be reproduced from anywhere in the world."

"Where are the clinical rotations?
Where's the hands-on?" he asks, explaining that Global University "is not intended to cover the clinical years. The clinical years are going to be through further relationships in countries where students get the patient exposure. We're going to provide the didactic content that they're going to use."

"There are all these remarkable resources that exist, and they aren't being used sufficiently," says Frank. "This has the opportunity to transform health outcomes around the world, and to transform health education around the world. It's going to be hugely powerful." - David Yin, Ottawa, Ont.

CMAJ 2011. DOI:10.1503/cmaj.109-3774 